\title{
Achieving Salt Restriction in Chronic Kidney Disease
}

\author{
Emma J. McMahon,, ${ }^{1,2}$ Katrina L. Campbell, ${ }^{1,2}$ David W. Mudge, ${ }^{1,2,3}$ and Judith D. Bauer ${ }^{2}$ \\ ${ }^{1}$ Nutrition and Dietetics Department, Princess Alexandra Hospital, 199 Ipswich Road, Woolloongabba, Brisbane, QLD 4102, Australia \\ ${ }^{2}$ School of Human Movement Studies, University of Queensland, Blair Drive, St Lucia, Brisbane, QLD 4072, Australia \\ ${ }^{3}$ Department of Nephrology, Princess Alexandra Hospital, University of Queensland, Ipswich Road, Woolloongabba, \\ Brisbane, QLD 4102, Australia
}

Correspondence should be addressed to Emma J. McMahon, e.hall5@uq.edu.au

Received 19 July 2012; Accepted 29 October 2012

Academic Editor: Siren Sezer

Copyright (c) 2012 Emma J. McMahon et al. This is an open access article distributed under the Creative Commons Attribution License, which permits unrestricted use, distribution, and reproduction in any medium, provided the original work is properly cited.

\begin{abstract}
There is consistent evidence linking excessive dietary sodium intake to risk factors for cardiovascular disease and chronic kidney disease (CKD) progression in CKD patients; however, additional research is needed. In research trials and clinical practice, implementing and monitoring sodium intake present significant challenges. Epidemiological studies have shown that sodium intake remains high, and intervention studies have reported varied success with participant adherence to a sodium-restricted diet. Examining barriers to sodium restriction, as well as factors that predict adherence to a low sodium diet, can aid researchers and clinicians in implementing a sodium-restricted diet. In this paper, we critically review methods for measuring sodium intake with a specific focus on CKD patients, appraise dietary adherence, and factors that have optimized sodium restriction in key research trials and discuss barriers to sodium restriction and factors that must be considered when recommending a sodium-restricted diet.
\end{abstract}

\section{Introduction}

Reducing cardiovascular risk and chronic kidney disease (CKD) progression are two of the primary goals of CKD management [1, 2]. Excessive sodium intake has been extensively researched for its relationship with cardiovascular risk factors, in particular hypertension and volume overload [3-5]. New research has indicated that dietary sodium intake may influence other novel, uremia-related risk factors in CKD, including oxidative stress, proteinuria, inflammation, and endothelial cell damage, and can increase cardiovascular risk, independent of blood pressure changes [2, 6-9].

Individuals with impaired kidney function may be particularly susceptible to the adverse effects of excessive sodium intake [2]. As sodium handling is primarily the role of the kidney [10], those with CKD may have a reduced ability to excrete sodium, making them less able to compensate for the high sodium load that is characteristic of the Western diet [10-12]. A recent review of the evidence for the relationship between salt intake and CKD progression concluded there is consistent evidence to suggest that dietary salt intake is linked with albuminuria and tissue injury, although acknowledged that empirical evidence is lacking [7]. Increased sodium intake is linked to reduced GFR [6], although this is somewhat controversial; increased sodium intake leads to increased glomerular pressure [13] causing short-term hyperfiltration that initially increases GFR [14]. However, this increased glomerular capillary pressure increases proteinuria, an independent risk factor for GFR decline and CVD $[15,16]$. Several trials have indicated improved efficacy of antiproteinuric agents with decreased sodium intake, suggesting that sodium can act as an antagonist to these drugs $[6,17]$. Animal studies have demonstrated increased proteinuria on a high sodium compared to a low sodium diet [18] and a relationship between sodium intake and albuminuria has been observed in the general population [16], although this has not been well explored in CKD.

There is compelling evidence that reducing dietary sodium can reduce cardiovascular risk and risk for kidney function decline in CKD patients, while being a costeffective intervention with low risk of adverse effects [19]. However, like medications will only be effective if taken as prescribed, a recommendation to reduce dietary sodium 
will only reduce cardiovascular and CKD progression if adherence is achieved. Poor adherence to sodium restriction is an ongoing problem in research trials and in the clinical practice setting [20]. Nonadherence in these two settings present two distinct issues: nonadherence in research trials may greatly underestimate the effect of the intervention, obscuring the diet-disease relationship, while nonadherence in the practice setting can impede reduction of disease risk, as well as interfering with the efficacy of some medications, potentially increasing risk of adverse outcome. The aim of this critical paper is to evaluate adherence to sodium restriction, including measurement methods, the degree of adherence achieved in research trials, recommendations for intake, and factors related to greater adherence to sodium restriction.

\section{Measurement of Sodium Intake in CKD}

It is imperative to measure dietary adherence in a dietary intervention trial to ensure changes seen in outcomes are attributable to changes in intake. There are several objectives and self-reported methods available for measurement of sodium intake; however, there are errors inherent in all methods and the strengths and limitations of each method must be taken into consideration (see Table 1) [21].

2.1. Urinary Sodium. As nearly all sodium ingested is excreted in the urine, repeated 24-hour urine measurements are considered by the World Health Organisation to be gold standard [21]. However, as sodium intake can vary significantly from day to day, accuracy of 24-hour urinary excretion to reflect sodium intake over a given time is directly related to the number of collections gathered [22]. When examining the potential effect of day to day variation in sodium intake on outcomes in research trials, Lui et al. estimated that the correlation between sodium and an outcome variable (e.g., blood pressure) could be weakened by half if a single measurement of 24-hour urinary sodium excretion was used [23]. This study estimated that even with four measurements of 24-hour urinary sodium excretion, potential correlations could be diminished by $25 \%$ (compared with 10 days) [23]. However, increased number of samples involve higher participant burden, increasing the likelihood of error related to improper collection [21]. For this reason, it is recommended to supplement 24hour urinary sodium measurements with other methods to maximise accuracy of estimated dietary sodium intake [21].

Spot urinary sodium, or sodium to creatinine ratio $(\mathrm{Na}: \mathrm{Cr})$, is an objective measure of dietary sodium intake with relatively smaller participant burden than 24-hour collection. The validity of this measure to represent sodium intake is contentious, particularly in CKD where excretion of these solutes may be deranged [12]. There has been little research in this area; however, two recent studies provide favourable results as a surrogate marker of sodium intake [24, 25]. Ogura et al. (2012) [26] assessed spot urinary sodium values extrapolated to estimations of 24-hour urinary sodium excretion using Tanaka's formula [26] and the agreement with actual 24-hour sodium excretion in 96 CKD patients [25]. Using Bland-Altman analysis, mean difference between estimated (from spot urine) and measured 24-hour urinary sodium excretion was $-10.9 \mathrm{mmol}$ with $94 \%$ of the values lying within 1.96 standard deviations of the mean difference, suggesting good agreement [25]. Kang et al. also compared spot urinary sodium to 24hour urinary sodium excretion in $305 \mathrm{CKD}$ patients, and found that the correlation between mean of three spot samples taken at different times of the day and 24-hour urinary sodium excretion was 0.477 (95\% CI: $0.384-0.562$; $P<0.01)$ for spot urinary sodium and $0.313(0.207-$ $0.415,<0.01)$ for spot urinary sodium to creatinine ratio [24]. However, these correlations, although significant, are weak and indicate associations rather than agreement. Given the lower participant burden and that spot urinary samples are often taken as part of standard practice, the validity of spot sodium or $\mathrm{Na}$ : $\mathrm{Cr}$ to represent intake in $\mathrm{CKD}$ warrants further investigation.

\subsection{Dietary Assessment Methods. Taking into consideration} the limitations of urinary sodium measures when estimating habitual intake, it is wise to employ self-reported dietary methods alongside these objective methods [21, 27]. There are several methods of self-report available to assess sodium intake; the method chosen should consider the inherent strengths and limitations (see Table 1), as well as the aim of the study, the population in question and time and resources available. Dietary intake assessment methods have been comprehensively reviewed (with respect to the general population) elsewhere [21]. As the validity of a self-reported measure of sodium intake is unlikely to differ when used in those with or without impaired kidney function, this paper will discuss self-reported methods only briefly.

The diet history, where information about what is eaten over an extended period of time is collected using openended questions [28], is considered to be a useful method for capturing usual intake [29] and aligns closest to dietary assessment methods used in clinical practice [30]. This method has performed favourably when compared with other dietary assessment methods such as food records or 24-hour recall [31] and has been comprehensively reviewed with respect to nutrients other than sodium [29]. A study of 60 young omnivores and vegans in Sweden found sodium estimations from diet history to be within $9 \mathrm{mmol}$ (198 $\mathrm{mg}$ ) of mean urinary sodium excretion from four 24-hour urine collections [32], suggesting good agreement. There are several advantages inherent in the diet history method; the presence of interviewer maintains participant interest and enables clarification of misunderstandings, information collected is not limited to a finite list of foods, and an interviewer skilled in dietary methodology is able to target foods that are likely to contribute significant amounts of sodium to the diet $[29,33]$. However, this method, like all retrospective methods (i.e., diet history, 24-hour recall, food frequency questionnaire), is susceptible to error related to memory lapse and reporting bias [34]. In addition, accuracy 
TABLe 1: Summary of measures that can be used to estimate sodium intake.

\begin{tabular}{|c|c|c|c|c|}
\hline Measure & Objectivity & Burden & Strengths & Limitations \\
\hline $\begin{array}{l}\text { 24-hour urinary } \\
\text { sodium }\end{array}$ & Objective & High & $\begin{array}{l}\text { (i) Gold standard } \\
\text { (ii) Accurately quantifies actual } \\
\text { intake when collected correctly }\end{array}$ & $\begin{array}{l}\text { (i) Under/overcollection can introduce error } \\
\text { (ii) High participant burden } \\
\text { (iii) High cost of analysis } \\
\text { (iv) Does not account for daily variation }\end{array}$ \\
\hline $\begin{array}{l}\text { Spot urinary } \\
\text { sodium }\end{array}$ & Objective & Low & $\begin{array}{l}\text { (i) Low participant burden } \\
\text { (ii) Quick to collect } \\
\text { (iii) Can be used as part of } \\
\text { standard practice }\end{array}$ & $\begin{array}{l}\text { (i) Does not account for diurnal variation } \\
\text { (ii) Further research needed to determine if valid } \\
\text { indicator of daily intake }\end{array}$ \\
\hline $\begin{array}{l}\text { Open-ended diet } \\
\text { history }\end{array}$ & Self-report & Moderate & $\begin{array}{l}\text { (i) Most comprehensive of } \\
\text { self-reported measures } \\
\text { (ii) Presence of interviewer } \\
\text { allows for verification and } \\
\text { clarification of information } \\
\text { provided } \\
\text { (iii) Retrospective nature allows } \\
\text { for assessment of "usual intake" }\end{array}$ & $\begin{array}{l}\text { (i) Time consuming to collect and code } \\
\text { (ii) Prone to memory lapse and reporting bias } \\
\text { (iii) Specialized skills and knowledge of food } \\
\text { supply required }\end{array}$ \\
\hline 24-hour recall & Self-report & Low & $\begin{array}{l}\text { (i) Standardized } \\
\text { (ii) Can be implemented over the } \\
\text { phone } \\
\text { (iii) Multiple administrations } \\
\text { increases validity } \\
\text { (iv) Best for larger } \\
\text { population-based studies }\end{array}$ & $\begin{array}{l}\text { (i) Does not account for daily variation in intake } \\
\text { (unless repeated) } \\
\text { (ii) Prone to reporting bias }\end{array}$ \\
\hline $\begin{array}{l}\text { Food records } \\
\text { (diaries) }\end{array}$ & Self-report & $\begin{array}{l}\text { Depends on } \\
\text { number of } \\
\text { days }\end{array}$ & $\begin{array}{l}\text { (i) Precise estimation of actual } \\
\text { intake on the days where recording } \\
\text { occurs, when completed correctly }\end{array}$ & $\begin{array}{l}\text { (i) Subject to participant motivation } \\
\text { (ii) Increased number of days increases } \\
\text { participant burden } \\
\text { (iii) Prone to under-reporting } \\
\text { (iv) Prone to modification of intake on days } \\
\text { where recording occurs }\end{array}$ \\
\hline $\begin{array}{l}\text { Food frequency } \\
\text { questionnaire }\end{array}$ & Self-report & Low & $\begin{array}{l}\text { (i) Standardized } \\
\text { (ii) Quick to administer } \\
\text { (iii) Easily coded } \\
\text { (iv) Many validation studies }\end{array}$ & $\begin{array}{l}\text { (i) Validity can depend on population in question } \\
\text { and food supply. } \\
\text { (ii) Subject to memory lapse; inability to } \\
\text { summarize intake; false perception of own intake. } \\
\text { (iii) Collects information about a limited number } \\
\text { of foods } \\
\text { (iv) Difficult to measure discretionary salt usage }\end{array}$ \\
\hline
\end{tabular}

of the method depends on the skills and training of the interviewer $[27,30]$.

Food records (or food diaries) are a common method for measuring intake in dietary trials as they are easy to administer and the prospective nature of the method limits error related to memory lapse [29]; however, the accuracy of this method to assess usual intake is questionable. Systematic bias is found, with a tendency to underestimate intake compared with objective markers [35-37]. For example, Day et al. found that a 7-day food record underestimated intake by approximately $17 \%$ when compared with urinary sodium excretion [35]. Correct recording of actual intake requires motivated participants [38]. In addition, the burden of keeping accurate food records can affect intake; study participants have reported reduced intake of snacks and other foods, and decreased complexity of the diet on days that food records are kept $[39,40]$. For example, in the Hypertension Prevention Trial, $48 \%$ of participants reported modifying their diet on days where records were kept, with those who were assigned a sodium-restricted diet eating more low sodium foods (or less salt/salty foods) on recording days [36]. While increasing the number of recording days increases likelihood of capturing "usual intake," this also increases participant burden. Rebro et al. found intake calculated from food records was lower on day four compared with day one, with lower number of foods recorded, and lower estimates of energy, carbohydrate, and other nutrients [39]. For these reasons, using food records to indicate intake over an entire intervention, or "usual" intake in a practical setting, may misrepresent intake [41].

The $24 \mathrm{hr}$ recall method refers to collecting information retrospectively about all foods and fluids consumed over the previous 24 hours [29]. This method is quick and inexpensive to administer, but does not account for dayto-day variation in intake $[42,43]$, meaning that it may not give an accurate estimation of habitual intake, unless 
repeated [44]. This method is also subject to memory lapse and reporting bias. When 24-hour recall was compared to 24-hour urinary collection, Espeland et al. found that participants underestimated their sodium intake by $22 \%$ and that the underestimation was larger in the treatment group recommended low sodium than other groups $[45,46]$. In order to decrease error by memory lapse, the United States Department of Agriculture (USDA) developed the five-step multiple-pass 24-hour recall method which consists of steps where participants: list the foods, are questioned on categories of foods that have been documented as frequently forgotten, report the time and occasion foods were consumed, are asked for further information on descriptions of foods and amounts eaten (aided by the use of the USDA Food Model Booklet and measuring guides), and finally review of information given [47]. Validation studies specific to sodium are lacking, but when validated against estimates of energy intake from doubly labelled water [48] and direct observation [49], this method has been found to be a valid tool for estimation of group intake, but not to give a precise estimate of individual intake, suggesting it may be most suited to epidemiological research.

A food frequency questionnaire (FFQ) is a questionnaire in which the respondent is presented with a list of foods and is asked to identify the frequency each is eaten in broad terms (e.g., per day/per week) [50]. Charlton et al. developed a FFQ specifically to estimate sodium intake and found that the estimation of sodium was strongly correlated with repeated 24-hour sodium excretion $(r=50.683, P<0.0001)$ [51]. However, the FFQ had a sensitivity of only $12.4 \%(27 / 218)$ to classify patients as having an intake under $<100 \mathrm{mmol}$ and specificity of $93.9 \%(62 / 66)$ to identify patients with intake $\geq 100 \mathrm{mmol}$ suggesting the questionnaire may underestimate intake. Other studies that have validated FFQs-designed to quantify a range of nutrients including sodium-against urinary sodium excretion have reported similar results [35, 52]. One of the difficulties with using a FFQ to estimate sodium intake stems from the ubiquitous nature of sodium in the food supply, meaning that a comprehensive list of foods is needed to capture intake. In addition, memory lapse, reporting bias, difficulty estimating portion sizes, and difficulty calculating discretionary salt usage can further increase risk of error [51, 53, 54]. Furthermore, differences in food supply and intake between populations may mean a particular FFQ and its scoring may be more accurate in some populations than others [55].

\section{Adherence to Sodium Restriction in Clinical Trials}

Several studies of sodium restriction have experienced difficulty with patient adherence to the specified sodium target $[8,56,57]$. Table 2 shows a summary of adherence in key trials of sodium restriction. Notably, those with intensive methods for delivering the interventions, particularly those that employed total food provision, achieved excellent adherence $[4,58]$. The DASH trial employed several methods to ensure dietary adherence [58]. All food was provided to participants for the month long study, a minimum one meal per day was eaten on-site (decreasing opportunities for nonadherence), and incentives including prizes and monetary reimbursement were provided to encourage adherence [58]. Multiple methods to measure dietary adherence were also used, including 24-hour urinary sodium excretion, daily diaries and a poststudy anonymous survey. These parameters indicated excellent adherence, with a mean urinary sodium excretion of $67 \pm 46$ and $64 \pm 37 \mathrm{mmol}$ (DASH and control groups) for the strictest dietary sodium target of $50 \mathrm{mmol}$ per day, and complementary methods (daily diaries, poststudy survey) confirming excellent adherence. However, large standard deviations for urinary sodium excretions in the low sodium groups indicate considerable variability in adherence between participants [58].

Pimenta et al. used total food provision as a means for delivering the low sodium intervention and achieved a mean urinary sodium excretion of $46 \pm 27 \mathrm{mmol}$ per day (target $50 \mathrm{mmol} /$ day) [4], indicating closer adherence than that achieved in DASH with smaller variation between participants, although the intervention duration was considerably shorter. While these studies provide an indication of efficacy of sodium restriction for reducing BP in their respective populations, intensive methods such as these require significant monetary and other resources (cooking facilities, cafeteria for dining in) which are not always available to researchers or feasible for participants. In addition, they do not provide any indication of the effectiveness (i.e., whether these results are achievable in a practical setting).

Troyer et al. investigated whether providing only one meal per day to elderly participants for one year improved adherence to sodium restriction [59]. The dietary intake data shows negligible change in sodium intake at 6 or 12 months from baseline in both groups; however, this may be a reflection of the method for gathering dietary intake data, given that as 24-hour recall does not assess daily deviations in intake and may be subject to memory lapse.

Examples of trials where excellent dietary adherence was achieved without provision of food are provided by Luik et al., Gates et al., and Todd et al., where dietary education was used as the primary means for delivering the interventions (see Table 2) [14, 60, 61]. A key characteristic common to these studies is that the dietary education was individualized, often employing the use of registered dietitians, who have thorough knowledge of the nutritional content of foods as well as extensive training in dietary data collection and experience implementing dietary interventions. As this more closely reflects what occurs in usual practice when a patient is prescribed a low sodium diet, these trials can be said to measure effectiveness as well as efficacy of sodium restriction in their populations.

The literature provides numerous examples of sodium restriction trials that rely on single 24-hour urinary sodium collection to indicate dietary intake during the entire intervention $[62,63]$. However, doing so assumes that this single 24-hour collection is representative of sodium intake over the entire intervention, and, as described previously, using a single measurement can considerably obscure the dietdisease relationship [23]. 


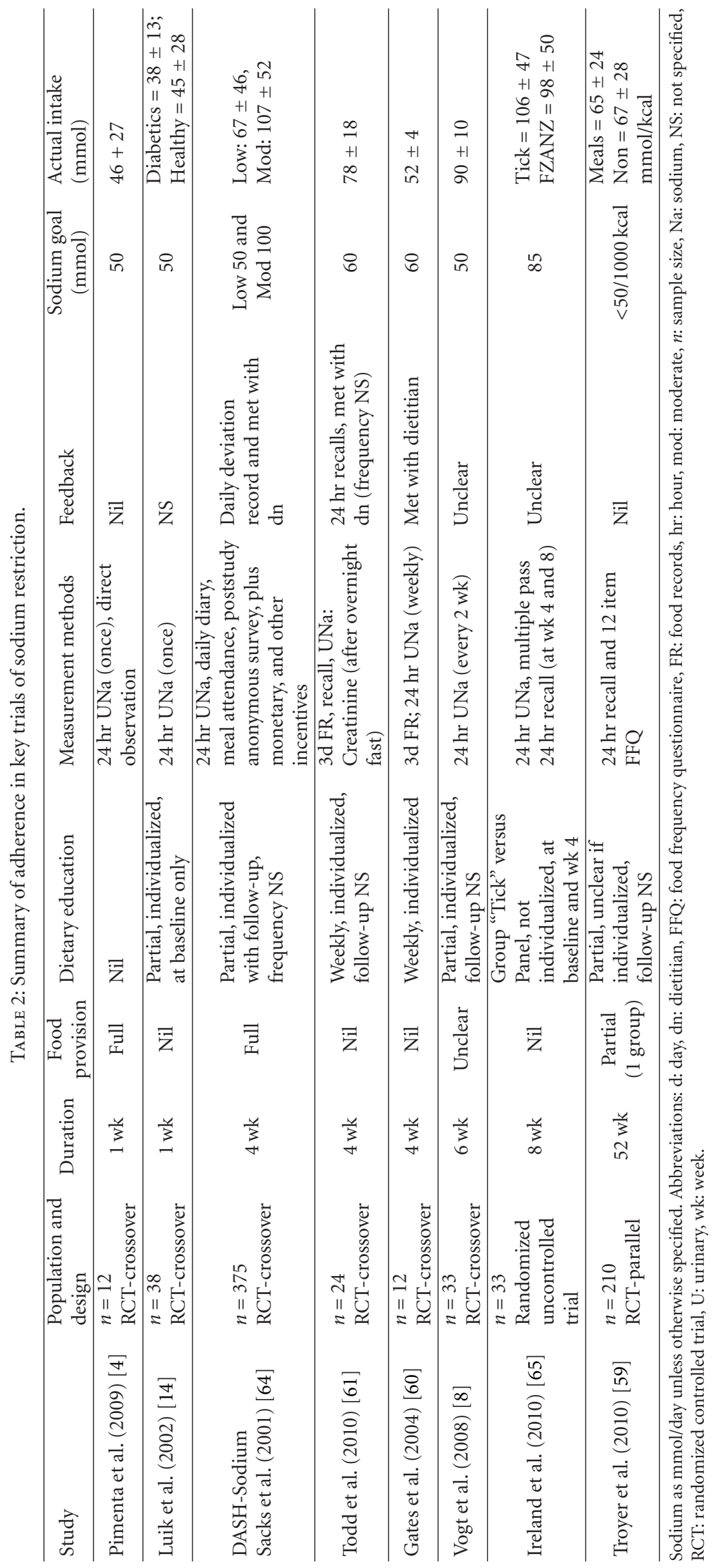


TABLE 3: Summary of studies investigating barriers to adhering to a sodium-restricted diet.

\begin{tabular}{|c|c|c|}
\hline Study country & Population & Barriers to sodium-restricted diet \\
\hline $\begin{array}{l}\text { Welch et al. (2006) [20] } \\
\text { USA }\end{array}$ & $\begin{array}{l}229 \text { hemodialysis pts, aged } \\
55 \pm 14 \text { years. } 58 \% \text { male, } 79 \% \\
\text { African American }\end{array}$ & $\begin{array}{l}\text { (i) Taste }(58 \%) \\
\text { (ii) Difficulty when eating out (30\%) } \\
\text { (iii) Cost }(23 \%) \\
\text { (iv) Difficult to understand }(21 \%) \\
\text { (v) Too time-consuming }(17 \%)\end{array}$ \\
\hline $\begin{array}{l}\text { De Brito-Ashurst et al. (2011) } \\
\text { [72] } \\
\text { UK }\end{array}$ & $\begin{array}{l}20 \text { female } C K D \text { pts, } 1 \text { st generation } \\
\text { immigrants from Bangladesh to the UK, } \\
\text { aged } 60 \pm 8 \text { years; unemployed }\end{array}$ & $\begin{array}{l}\text { (i) Lack of family acceptance }(50 \%, n=10 / 20) \\
\text { (ii) Fear that friends will gossip/think the family has } \\
\text { no money }(40 \%, 8 / 20) \\
\text { (iii) No perceived benefit }(25 \%, n=5 / 20)\end{array}$ \\
\hline
\end{tabular}

Gordon et al. (2009) [77] 82 transplant recipients aged USA

(i) Preferences for salty foods and enjoying taste of salt $(n=9)$ (ii) Lack of available low-salt dishes at restaurants $(n=10)$ or low-salt foods in markets $(n=3)$ and when other people cook using salt $(n=3)$

(iii) Lifestyle factors $(n=5)$ for example, having no time to cook

43 healthy pts from volunteer database. $23 \%$ (i) Limited variety of appropriate foods

Ireland et al. (2010) [65] Australia male, aged $55 \pm 11$ in "tick group"

(ii) Difficulty eating out $57 \pm 13$ y in "FSANZ group"

(iii) Increased time for shopping

(i) Trouble choosing foods in restaurants (75\%)

(ii) Favorite foods aren't low-salt (72\%)

(iii) Taste (69\%)

(iv) Favorite restaurants don't serve low-salt foods (64\%)

Chung et al. (2006) [78]

Australia and United States
68 heart failure patients, aged $63 \pm 14$ years, $60 \%$ male, $63 \%$ Caucasian (v) Insufficient will power to change diet (59\%)

(vi) Peers don't eat low-salt foods (54\%)

(vii) Trouble choosing foods at supermarket (52\%)

(viii) Poor knowledge/understanding (49\%)

(ix) Cost $(47 \%)$

(x) Does not cook $(40 \%)$

(xi) Time to prepare food (38\%)

(xii) Person who cooks doesn't prepare low-salt foods (30\%)

(i) Lack of knowledge (need for more detailed dietary information, confusion for pts with additional dietary restrictions)

(ii) Lack of perceived benefit

(iii) Interference with socialization (family conflict, difficulty eating out)

(iv) Limited food choices/lack of palatability
Bentley et al. (2005) [79] USA provider's recommendation to follow a low sodium diet, aged $60 \pm 11$ years $60 \%$ male, $80 \%$ non-Hispanic White

Figures as mean \pm standard deviation. Abbreviations: CKD: chronic kidney disease, FSANZ: Food Standards Australia New Zealand, Pts: participants.

\section{Sodium Intakes in the Clinical Setting}

Most guidelines specific to the nutritional management of CKD patients recommend an upper limit of $100 \mathrm{mmol}$ of sodium per day (2300 mg, $6 \mathrm{~g} \mathrm{NaCl}$ ) [66-69]. The United States dietary guidelines recommend a stricter target of $<65 \mathrm{mmol}$ per day for people with CKD (1495 mg, $3.8 \mathrm{~g}$ ) [70]. Mean 24-hour urinary sodium excretion in large studies suggests that CKD patients commonly have urinary sodium excretions between 150 and $200 \mathrm{mmol}$, far above the recommendations [71-75]. In fact, the rate of adherence to a sodium target of less than $100 \mathrm{mmol}$ per day is met by only $13-19 \%[2,75,76]$.

Influences on dietary behaviors are complex and mediated by a number of factors [71]. Barriers specific to dietary sodium restriction that arise frequently in the literature can be summarized as being related to (i) perceived taste/palatability of low sodium foods,

(ii) convenience/difficulty (e.g., time, availability of low sodium foods, interference with socialization, and cost) or,

(iii) lack of knowledge or understanding (e.g., lack of perceived benefit and inability to identify low sodium foods) (Table 3 [20, 65, 77-79]).

An observational study by Welch et al. measured barriers and enablers to following a low sodium diet in hemodialysis patients in the USA [20]. While nearly all participants indicated that they agreed that a low salt diet would make them feel better and keep their blood pressure down, the majority reported taste as a barrier. In addition, a considerable proportion of participants reported difficulty when eating out, cost, and difficulty understanding a low sodium diet as barriers [20]. 
De Brito-Ashurst et al. also examined barriers to a low sodium diet in immigrants to the UK and emphasized the importance for individualized messages, stating that "provision of generic low sodium information had led participants to believe they did not have a high sodium intake, paradoxically deterring dietary sodium reduction" [72]. Health care practitioners may find it is common for patients to report that they consume very little salt, despite having high urinary sodium excretion. Discretionary salt (salt added to food) is a relatively small contributor to sodium intake compared with salt already in the foods on the shelves $[73,74]$. There are many foods that do not taste salty despite high sodium content, for example, certain breakfast cereals and sweet biscuits, making it difficult to follow a low sodium diet without paying close attention to nutrition information panels.

Evidence suggests that hedonic liking and taste sensitivity of salty taste can be modified with adherence to a low sodium diet [75]. Mattes studied 8 normotensive adults and, while at baseline regular sodium products were preferred to reduced sodium versions, after four months of sodium restriction there was no significant difference in preference for these products [76]. Kusaba et al. found that taste sensitivity in CKD patients was improved after only one week of adherence to a low sodium diet [62]; however, given the short-term nature of the study, and the fact that adherence to the sodium-restricted diet was not measured (although all meals were consumed on site as participants were inpatients), this is an area that warrants further investigation.

\section{Conclusion and Recommendations}

Excessive sodium intake shows promise as a modifiable risk factor to reduce cardiovascular risk and risk for $\mathrm{CKD}$ progression in CKD patients; however, research in this area is not yet conclusive. Researchers planning to explore this area further must take the issues presented in this paper into consideration; it is imperative to measure sodium intake in a sodium restriction trial (or any trial where sodium is a variable that could affect the outcome in question). The measurement methods chosen to assess sodium intake must consider the inherent limitations. Undertaking a panel of measures is optimal.

Using a single 24-hour urinary sodium excretion to represent intake over a dietary intervention can greatly underestimate the efficacy of sodium reduction. While repeated 24-hour sodium excretion is gold standard for measuring intake, these are not always practical. Spot urinary sodium samples entail considerably lower participant burden, but further research in CKD needs to be conducted to ascertain if these are valid indicator of total intake. Supplementing 24-hour urine samples with other self-reported measures such as open-ended, interviewer-administered diet history is recommended.

Patient adherence to sodium restriction must be taken into account when examining the effect on a particular outcome. Several trials have reported poor adherence. Tightly controlled feeding studies have achieved excellence adherence, but researchers do not always have the resources required to conduct these. Where dietary education is given, using an individualized approach may enhance adherence.

Sodium intakes in the general population and in CKD patients are far above that recommended. Health care practitioners must take barriers to sodium restriction into consideration when recommending a low-sodium diet. Using an individualized approach is also useful in practice.

\subsection{Key Recommendations}

(i) When designing a research trial where sodium intake is to be measured, consider the strengths and limitations of available methods.

(ii) Where possible, use a panel of methods, including self-report (e.g., diet history method) alongside objective markers (e.g., 24-hour urinary sodium) to assess intake.

(iii) Food provision and provision of individualized dietary education aid adherence to sodium restriction in a research trial.

(iv) Employing a registered dietitian skilled in dietary assessment and individualized dietary education may enhance the effectiveness of an intervention.

(v) Consider barriers to a low sodium diet when advising a low sodium diet; perceived taste/palatability of low sodium foods, convenience/difficulty, and lack of knowledge or understanding (e.g., lack of perceived benefit, inability to identify low sodium foods) are barriers to sodium restriction.

\section{Acknowledgments}

The authors would like to thank the University of Queensland and Princess Alexandra Hospital for their ongoing support. E. J. McMahon is supported by the Australian Government through an Australian Postgraduate Award scholarship. K. L. Campbell is supported by a Queensland Government's Office of Health and Medical Research Fellowship and a Lions Senior Medical Research Fellowship.

\section{References}

[1] A. J. Kallen and P. R. Patel, "In search of a rational approach to chronic kidney disease detection and management," Kidney International, vol. 72, no. 1, pp. 3-5, 2007.

[2] J. A. Krikken, G. U. Laverman, and G. Navis, "Benefits of dietary sodium restriction in the management of chronic kidney disease," Current Opinion in Nephrology and Hypertension, vol. 18, no. 6, pp. 531-538, 2009.

[3] R. J. Suckling, F. J. He, and G. A. Macgregor, "Altered dietary salt intake for preventing and treating diabetic kidney disease," Cochrane Database of Systematic Reviews, vol. 12, Article ID CD006763, 2010.

[4] E. Pimenta, K. K. Gaddam, S. Oparil et al., "Effects of dietary sodium reduction on blood pressure in subjects with resistant hypertension: results from a randomized trial," Hypertension, vol. 54, no. 3, pp. 475-481, 2009. 
[5] M. Essig, B. Escoubet, D. De Zuttere et al., "Cardiovascular remodelling and extracellular fluid excess in early stages of chronic kidney disease," Nephrology Dialysis Transplantation, vol. 23, no. 1, pp. 239-248, 2008.

[6] S. Thijssen, T. M. Kitzler, and N. W. Levin, "Salt: its role in chronic kidney disease," Journal of Renal Nutrition, vol. 18, no. 1, pp. 18-26, 2008.

[7] C. Jones-Burton, S. I. Mishra, J. C. Fink et al., "An indepth review of the evidence linking dietary salt intake and progression of chronic kidney disease," American Journal of Nephrology, vol. 26, no. 3, pp. 268-275, 2006.

[8] L. Vogt, F. Waanders, F. Boomsma, D. De Zeeuw, and G. Navis, "Effects of dietary sodium and hydrochlorothiazide on the antiproteinuric efficacy of losartan," Journal of the American Society of Nephrology, vol. 19, no. 5, pp. 999-1007, 2008.

[9] E. Ritz, R. Dikow, C. Morath, and V. Schwenger, "Salt-a potential "uremic toxin"?" Blood Purification, vol. 24, no. 1, pp. 63-66, 2006.

[10] P. Strazzullo, F. Galletti, and G. Barba, "Altered renal handling of sodium in human hypertension: short review of the evidence," Hypertension, vol. 41, no. 5, pp. 1000-1005, 2003.

[11] G. Kimura, Y. Dohi, and M. Fukuda, "Salt sensitivity and circadian rhythm of blood pressure: the keys to connect CKD with cardiovasucular events," Hypertension Research, vol. 33, no. 6, pp. 515-520, 2010.

[12] H. A. Koomans, J. C. Roos, and P. Boer, "Salt sensitivity of blood pressure in chronic renal failure. Evidence for renal control of body fluid distribution in man," Hypertension, vol. 4, no. 2, pp. 190-197, 1982.

[13] M. Vedovato, G. Lepore, A. Coracina et al., "Effect of sodium intake on blood pressure and albuminuria in Type 2 diabetic patients: the role of insulin resistance," Diabetologia, vol. 47, no. 2, pp. 300-303, 2004.

[14] P. T. Luik, K. Hoogenberg, F. G. H. Van der Kleij et al., "Short-term moderate sodium restriction induces relative hyperfiltration in normotensive normoalbuminuric Type I diabetes mellitus," Diabetologia, vol. 45, no. 4, pp. 535-541, 2002.

[15] F. H. Messerli, R. E. Schmieder, and M. R. Weir, "Salt: a perpetrator of hypertensive target organ disease?" Archives of Internal Medicine, vol. 157, no. 21, pp. 2449-2452, 1997.

[16] J. C. Verhave, H. L. Hillege, J. G. Burgerhof et al., "Sodium intake affects urinary albumin excretion especially in overweight subjects," Journal of Internal Medicine, vol. 256, no. 4, pp. 324-330, 2004.

[17] J. E. Heeg, P. E. De Jong, G. K. Van der Hem, and D. De Zeeuw, "Efficacy and variability of the antiproteinuric effect of ACE inhibition by lisinopril," Kidney International, vol. 36, no. 2, pp. 272-279, 1989.

[18] I. Vaněčková, P. Škaroupková, P. Dvořák et al., "Effects of sodium restriction and cyclooxygenase-2 inhibition on the course of hypertension, proteinuria and cardiac hypertrophy in Ren-2 transgenic rats," Physiological Research, vol. 54, no. 1, pp. 17-24, 2005.

[19] G. Wang and D. Labarthe, "The cost-effectiveness of interventions designed to reduce sodium intake," Journal of Hypertension, vol. 29, no. 9, pp. 1693-1699, 2011.

[20] J. L. Welch, S. J. Bennett, R. L. Delp, and R. Agarwal, "Benefits of and barriers to dietary sodium adherence," Western Journal of Nursing Research, vol. 28, no. 2, pp. 162-180, 2006.

[21] P. Elliot and I. Brown, Sodium Intakes Around the World: Background Document Prepared for the Forum and Technical Meeting on Reducing Salt Intake in Populations, World Health Organisation, 2006.
[22] F. C. Luft, N. S. Fineberg, and R. S. Sloan, "Estimating dietary sodium intake in individuals receiving a randomly fluctuating intake," Hypertension, vol. 4, no. 6, pp. 805-808, 1982.

[23] K. Liu, R. Cooper, and J. McKeever, "Assessment of the association between habitual salt intake and high blood pressure: methodological problems," American Journal of Epidemiology, vol. 110, no. 2, pp. 219-226, 1979.

[24] S. S. Kang, E. H. Kang, S. O. Kim et al., "Use of mean spot urine sodium concentrations to estimate daily sodium intake in patients with chronic kidney disease," Nutrition, vol. 28, no. 3, pp. 256-261, 2012.

[25] M. Ogura, A. Kimura, K. Takane et al., "Estimation of salt intake from spot urine samples in patients with chronic kidney disease," BMC Nephrology, vol. 13, no. 1, p. 36, 2012.

[26] T. Tanaka, T. Okamura, K. Miura et al., "A simple method to estimate populational 24 -h urinary sodium and potassium excretion using a casual urine specimen," Journal of Human Hypertension, vol. 16, no. 2, pp. 97-103, 2002.

[27] S. A. Bingham, "Limitations of the various methods for collecting dietary intake data," Annals of Nutrition and Metabolism, vol. 35, no. 3, pp. 117-127, 1991.

[28] B. S. Burke, "The dietary history as a tool in research," Journal of the American Dietetic Association, vol. 23, pp. 1041-1046, 1947.

[29] G. Martin, “The interviewer-administered, open-ended diet history method for assessing usual dietary intakes in clinical research: relative and criterion validation studies," in Department of Biomedical Science, University of Wollongong, Wollongong, Australia, 2004.

[30] L. C. Tapsell and V. Brenninger, "Applying conversation analysis to foster accurate reporting in the diet history interview," Journal of the American Dietetic Association, vol. 100, no. 7, pp. 818-824, 2000.

[31] T. L. Bazzarre and J. A. Yuhas, "Comparative evaluation of methods of collecting food intake data for cancer epidemiology studies," Nutrition and Cancer, vol. 5, no. 3-4, pp. 201-214, 1983.

[32] C. L. Larsson and G. K. Johansson, "Dietary intake and nutritional status of young vegans and omnivores in Sweden," The American Journal of Clinical Nutrition, vol. 76, no. 1, pp. 100-106, 2002.

[33] A. E. Black, A. A. Welch, and S. A. Bingham, "Validation of dietary intakes measured by diet history against $24 \mathrm{~h}$ urinary nitrogen excretion and energy expenditure measured by the doubly-labelled water method in middle-aged women," British Journal of Nutrition, vol. 83, no. 4, pp. 341-354, 2000.

[34] M. Jain, G. R. Howe, and T. Rohan, "Dietary assessment in epidemiology: comparison of a food frequency and a diet history questionnaire with a 7-day food record," American Journal of Epidemiology, vol. 143, no. 9, pp. 953-960, 1996.

[35] N. E. Day, N. McKeown, M. Y. Wong, A. Welch, and S. Bingham, "Epidemiological assessment of diet: a comparison of a 7-day diary with a food frequency questionnaire using urinary markers of nitrogen, potassium and sodium," International Journal of Epidemiology, vol. 30, no. 2, pp. 309-317, 2001.

[36] J. L. Forster, R. W. Jeffery, M. VanNatta, and P. Pirie, "Hypertension prevention trial: do 24-h food records capture usual eating behavior in a dietary change study," The American Journal of Clinical Nutrition, vol. 51, no. 2, pp. 253-257, 1990.

[37] W. Mertz, J. C. Tsui, J. T. Judd et al., "What are people really eating? The relation between energy intake derived from estimated diet records and intake determined to maintain body weight," The American Journal of Clinical Nutrition, vol. 54, no. 2, pp. 291-295, 1991. 
[38] K. S. Todd, M. Hudes, and D. Howes Calloway, "Food intake measurement: problems and approaches," The American Journal of Clinical Nutrition, vol. 37, no. 1, pp. 139-146, 1983.

[39] S. M. Rebro, R. E. Patterson, A. R. Kristal, and C. L. Cheney, "The effect of keeping feed records on eating patterns," Journal of the American Dietetic Association, vol. 98, no. 10, pp. 1163$1165,1998$.

[40] I. M. Buzzard, C. L. Faucett, R. W. Jeffery et al., "Monitoring dietary change in a low-fat diet intervention study: advantages of using 24-hour dietary recalls vs food records," Journal of the American Dietetic Association, vol. 96, no. 6, pp. 574-579, 1996.

[41] M. R. Craig, A. R. Kristal, C. L. Cheney, and A. L. Shattuck, "The prevalence and impact of 'atypical' days in 4-day food records," Journal of the American Dietetic Association, vol. 100, no. 4, pp. 421-427, 2000.

[42] G. H. Beaton, J. Milner, and P. Corey, "Sources of variance of 24-hour dietary recall data: implications for nutrition study designing and interpretation," The American Journal of Clinical Nutrition, vol. 32, no. 12, pp. 2546-2559, 1979.

[43] G. H. Beaton, J. Milner, and V. McGuire, "Source of variance in 24-hour dietary recall data: implications for nutrition study design and interpretation. Carbohydrate sources, vitamins, and minerals," The American Journal of Clinical Nutrition, vol. 37, no. 6, pp. 986-995, 1983.

[44] I. H. E. Rutishauser, "Dietary intake measurements," Public Health Nutrition, vol. 8, no. 7, pp. 1100-1107, 2005.

[45] M. A. Espeland, S. Kumanyika, A. C. Wilson et al., "Statistical issues in analyzing 24-hour dietary recall and 24-hour urine collection data for sodium and potassium intakes," American Journal of Epidemiology, vol. 153, no. 10, pp. 996-1006, 2001.

[46] M. A. Espeland, S. Kumanyika, A. C. Wilson et al., "Lifestyle interventions influence relative errors in self-reported diet intake of sodium and potassium," Annals of Epidemiology, vol. 11, no. 2, pp. 85-93, 2001.

[47] P. M. Guenther, T. J. Demaio, L. A. Inowersen, and M. Berlin, "The multiple-pass approach for the 24-hour recall in the contmums survey of food intakes by individuals (CSFTI) 1994-96," FASEB Journal, vol. 10, no. 3, Article ID A198, 1996.

[48] R. K. Johnson, P. Driscoll, and M. I. Goran, "Comparison of multiple-pass 24-hour recall estimates of energy intake with total energy expenditure determined by the doubly labeled water method in young children," Journal of the American Dietetic Association, vol. 96, no. 11, pp. 1140-1144, 1996.

[49] J. M. Conway, L. A. Ingwersen, and A. J. Moshfegh, "Accuracy of dietary recall using the USDA five-step multiple-pass method in men: an observational validation study," Journal of the American Dietetic Association, vol. 104, no. 4, pp. 595-603, 2004.

[50] J. Cade, R. Thompson, V. Burley, and D. Warm, "Development, validation and utilisation of food-frequency questionnaires-a review," Public Health Nutrition, vol. 5, no. 4, pp. 567-587, 2002.

[51] K. E. Charlton, K. Steyn, N. S. Levitt, D. Jonathan, J. V. Zulu, and J. H. Nel, "Development and validation of a short questionnaire to assess sodium intake," Public Health Nutrition, vol. 11, no. 1, pp. 83-94, 2008.

[52] S. Sasaki, J. Ishihara, and S. Tsugane, "Validity of a selfadministered food frequency questionnaire in the 5-year follow-up survey of the JPHC Study Cohort I to assess sodium and potassium intake: comparison with dietary records and 24-hour urinary excretion level," Journal of Epidemiology, vol. 13, no. 1, pp. S102-S105, 2003.
[53] S. A. Bingham, C. Gill, A. Welch et al., "Comparison of dietary assessment methods in nutritional epidemiology: weighed records v. $24 \mathrm{~h}$ recalls, food-frequency questionnaires and estimated-diet records," British Journal of Nutrition, vol. 72, no. 4, pp. 619-643, 1994.

[54] E. Barrett-Connor, "Nutrition epidemiology: how do we know what they ate?" The American Journal of Clinical Nutrition, vol. 54, no. 2, pp. 182S-187S, 1991.

[55] S. Sharma, "Development and use of FFQ among adults in diverse settings across the globe," Proceedings of the Nutrition Society, vol. 70, no. 2, pp. 232-251, 2011.

[56] M. D. Murray, W. Tu, J. Wu, D. Morrow, F. Smith, and D. C. Brater, "Factors associated with exacerbation of heart failure include treatment adherence and health literacy skills," Clinical Pharmacology and Therapeutics, vol. 85, no. 6, pp. 651-658, 2009.

[57] G. Grassi, R. Dell'Oro, G. Seravalle, G. Foglia, F. Q. Trevano, and G. Mancia, "Short- and long-term neuroadrenergic effects of moderate dietary sodium restriction in essential hypertension," Circulation, vol. 106, no. 15, pp. 1957-1961, 2002.

[58] M. M. Windhauser, M. A. Evans, M. L. McCullough et al., "Dietary adherence in the dietary approaches to stop hypertension trial. DASH Collaborative Research Group," Journal of the American Dietetic Association, vol. 99, no. 8, supplement, pp. S76-S83, 1999.

[59] J. L. Troyer, E. F. Racine, G. W. Ngugi, and W. J. McAuley, "The effect of home-delivered Dietary Approach to Stop Hypertension (DASH) meals on the diets of older adults with cardiovascular disease," The American Journal of Clinical Nutrition, vol. 91, no. 5, pp. 1204-1212, 2010.

[60] P. E. Gates, H. Tanaka, W. R. Hiatt, and D. R. Seals, "Dietary sodium restriction rapidly improves large elastic artery compliance in older adults with systolic hypertension," Hypertension, vol. 44, no. 1, pp. 35-41, 2004.

[61] A. S. Todd, R. J. Macginley, J. B. Schollum et al., "Dietary salt loading impairs arterial vascular reactivity," The American Journal of Clinical Nutrition, vol. 91, no. 3, pp. 557-564, 2010.

[62] T. Kusaba, Y. Mori, O. Masami et al., "Sodium restriction improves the gustatory threshold for salty taste in patients with chronic kidney disease," Kidney International, vol. 76, no. 6, pp. 638-643, 2009.

[63] M. Alvelos, A. Ferreira, P. Bettencourt et al., "The effect of dietary sodium restriction on neurohumoral activity and renal dopaminergic response in patients with heart failure," European Journal of Heart Failure, vol. 6, no. 5, pp. 593-599, 2004.

[64] F. M. Sacks, L. P. Svetkey, W. M. Vollmer et al., "Effects on blood pressure of reduced dietary sodium and the dietary approaches to stop hypertension (dash) diet," The New England Journal of Medicine, vol. 344, no. 1, pp. 3-10, 2001.

[65] D. M. Ireland, P. M. Clifton, and J. B. Keogh, "Achieving the salt intake target of $6 \mathrm{~g} /$ day in the current food supply in freeliving adults using two dietary education strategies," Journal of the American Dietetic Association, vol. 110, no. 5, pp. 763-767, 2010.

[66] A. Levin, B. Hemmelgarn, B. Culleton et al., "Guidelines for the management of chronic kidney disease," Canadian Medical Association Journal, vol. 179, no. 11, pp. 1154-1162, 2008.

[67] S. Ash, K. Campbell, H. MacLaughlin et al., "Evidence based practice guidelines for the nutritional management of chronic kidney disease," Nutrition \& Dietetics, vol. 63, supplement s2, pp. S33-S45, 2006. 
[68] D. Fouque, M. Vennegoor, P. T. Wee et al., "EBPG guideline on nutrition," Nephrology Dialysis Transplantation, vol. 22, supplement 2, pp. ii45-ii87, 2007.

[69] D. Voss, Nutrition and Growth in Kidney Disease: Sodium in Pre-Dialysis Patients CARI Guidelines, Caring for Australians with Renal Impairment, 2005.

[70] U.S. Department of Agriculture and U.S., Department of Health and Human Services, Dietary Guidelines for Americans, Government Printing Office, Washington, DC, USA, 7th edition, 2010.

[71] National Health and Medical Research Council, "A review of the evidence to address targeted questions to inform the revision of the Australian Dietary Guidelines," 2011, https:// www.eatforhealth.gov.au/sites/default/files/files/public_consultation/n55_draft_australian_dietary_guidelines_consultation_111212.pdf.

[72] I. de Brito-Ashurst, L. Perry, T. A. B. Sanders, J. E. Thomas, M. M. Yaqoob, and H. Dobbie, "Barriers and facilitators of dietary sodium restriction amongst Bangladeshi chronic kidney disease patients," Journal of Human Nutrition and Dietetics, vol. 24, no. 1, pp. 86-95, 2011.

[73] W. P. T. James, A. Ralph, and C. P. Sanchez-Castillo, "The dominance of salt in manufactured food in the sodium intake of affluent societies," The Lancet, vol. 1, no. 8530, pp. 426-429, 1987.

[74] R. D. Mattes and D. Donnelly, "Relative contributions of dietary sodium sources," Journal of the American College of Nutrition, vol. 10, no. 4, pp. 383-393, 1991.

[75] R. Yensen, "Influence of salt deficiency on taste sensitivity in human subjects," Nature, vol. 181, no. 4621, pp. 1472-1474, 1958.

[76] R. D. Mattes, "The taste for salt in humans," The American Journal of Clinical Nutrition, vol. 65, no. 2, supplement, pp. 692S-697S, 1997.

[77] E. J. Gordon, T. R. Prohaska, M. Gallant, and L. A. Siminoff, "Self-care strategies and barriers among kidney transplant recipients: a qualitative study," Chronic Illness, vol. 5, no. 2, pp. 75-91, 2009.

[78] M. L. Chung, D. K. Moser, T. A. Lennie et al., "Gender differences in adherence to the sodium-restricted diet in patients with heart failure," Journal of Cardiac Failure, vol. 12, no. 8, pp. 628-634, 2006.

[79] B. Bentley, M. J. De Jong, D. K. Moser, and A. R. Peden, "Factors related to nonadherence to low sodium diet recommendations in heart failure patients," European Journal of Cardiovascular Nursing, vol. 4, no. 4, pp. 331-336, 2005. 


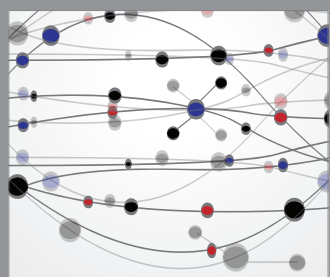

The Scientific World Journal
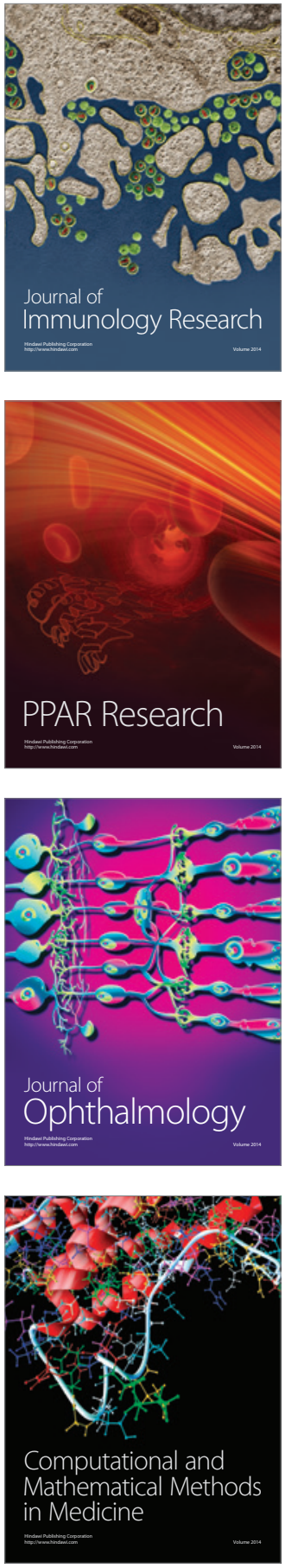

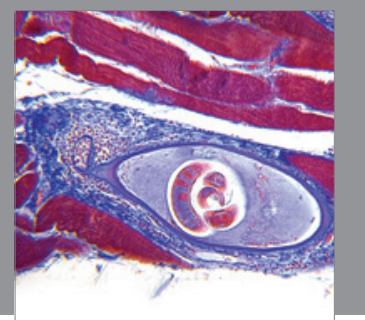

Gastroenterology

Research and Practice
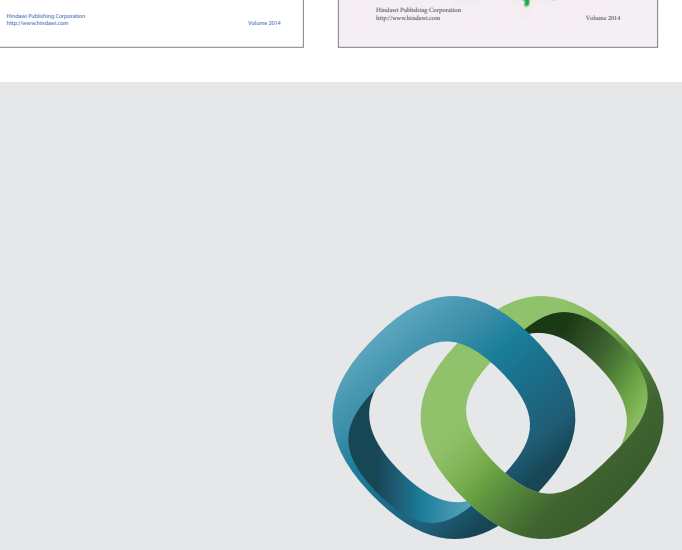

\section{Hindawi}

Submit your manuscripts at

http://www.hindawi.com
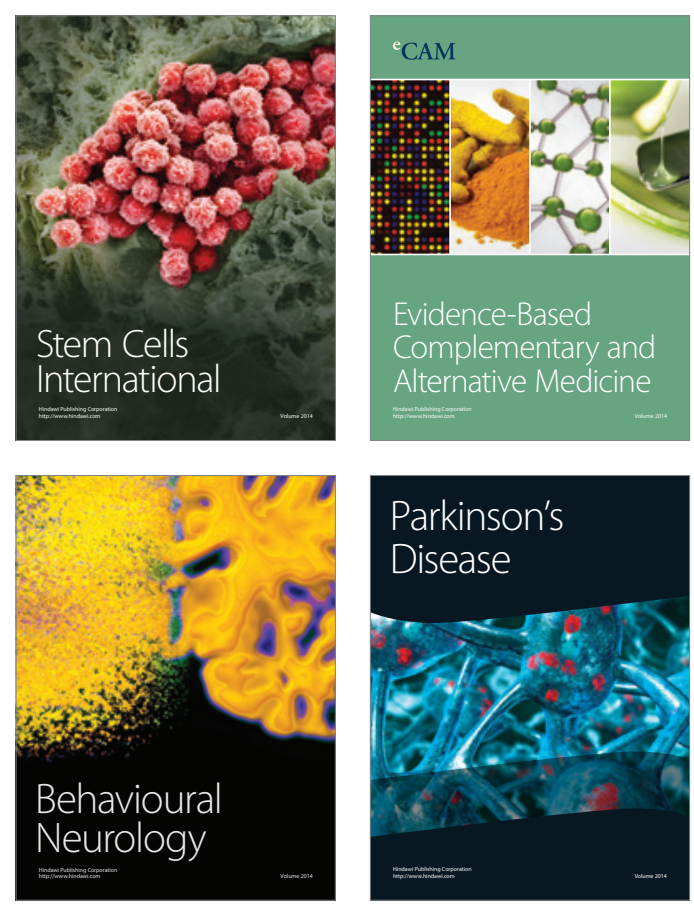

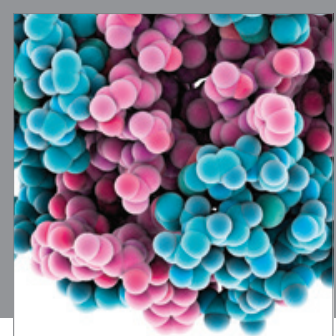

Journal of
Diabetes Research

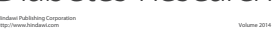

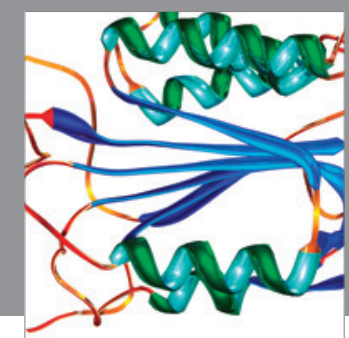

Disease Markers
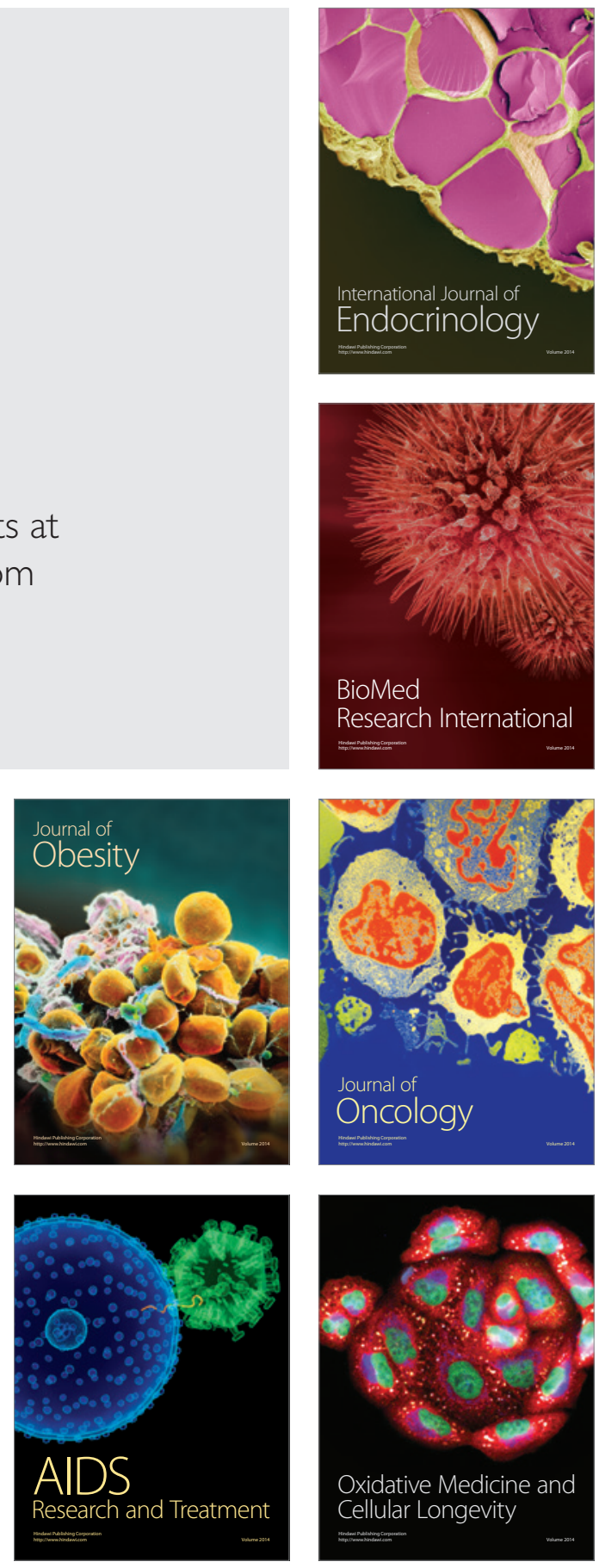